\title{
La Enfermería del Trabajo, una Especialidad reciente, una Profesión de siempre.
}

\author{
José Manuel Corbelle Álvarez
}

Presidente. Comisión Nacional Enfermería del Trabajo

La Enfermería del Trabajo es seguramente de las más antiguas y con mayor tradición dentro de la Enfermería Especializada en nuestro país. Tanto por su ámbito de actuación como por su necesaria formación específica, ha gozado históricamente de una identidad propia y claramente definida.

Aunque el reconocimiento y creación de la figura de los Enfermeros dedicados específicamente a la Salud Laboral se remonta a mediados del siglo pasado, este colectivo ha venido adaptándose a las necesidades sociales y laborales en su caminar hasta llegar a nuestros días. En este proceso ha recorrido un largo camino en el que se ha adquirido un vasto campo de conocimiento y experiencia, con el que se viene dando respuesta a las necesidades que surgen día a día en el desempeño de sus competencias, y donde la Escuela Nacional de Medicina del Trabajo, ha desempeñado una importate tarea que ha sido referencia para este colectivo.

El sustancial cambio que representó la normativa en Prevención de Riesgos Laborales, con el paso de un modelo puramente reactivo a unas actuaciones proactivas, pensadas en la prevención, la formación y la anticipación, proyectaron la figura del enfermero (de empresa hasta entonces) a funciones de nivel superior.

Estos nuevos conceptos también afectan al mismo concepto de Salud donde prevalece por encima de todo lo demás. El objetivo es tratar con personas sanas, en edad productiva y cuya salud no puede ni debe verse afectada por situaciones de riesgo de origen laboral. Mantener al menos la salud aunque trabajando por promocionar y potenciar la salud de los trabajadores, así como anticiparse ante su posible pérdida en la población trabajadora, es el gran reto. El concepto de enfermedad se aleja como objetivo inmediato, aun sin perderlo de vista. Por tanto la responsabilidad del Enfermero Especialista del Trabajo no debe circunscribirse a la vigilancia de la salud o a la atención de urgencia, en el plano asistencial, sino que debe extender su actividad a cualquier circunstancia que afecte o pueda afectar a la salud de los trabajadores, a formar e informar a los mismos, a promocionar la salud en los lugares de trabajo y a potenciar una estrecha colaboración con el Sistema Nacional de Salud.

Términos como exámenes y vigilancia de la salud, riesgos inherentes al puesto de trabajo, estado biológico conocido, trabajador especialmente sensible y muchos más, encierran en si mismos una forma de hacer la Enfermería netamente especializada. Para abordar con eficacia estas funciones, es necesario poseer las aptitudes, conocimientos y habilidades específicas para afrontar estas obligaciones. Aparecen nuevos conceptos alejados hasta ahora de la práctica habitual y de la formación de Enfermero Generalista o Grado en Enfermería.

En la misma línea de evolución aparecen nuevas necesidades, como la protección de datos. La confidencialidad de los datos de salud, su correcto uso y acceso, por parte de los profesionales sanitarios encargados de la atención de estos trabajadores, es imprescindible. Pero a la vez debe garantizarse que no podrán ser usados en perjuicio del trabajador. Es un imperativo legal, pero también es un principio éticoprofesional.

El seguimiento del estado de salud de los trabajadores, el adecuado y correcto registro, la observación y análisis de los datos de salud de cada trabajador, en una imprescindible historia clínico-laboral, componen un largo numero de actividades y procedimientos de trabajo en las que deben intervenir, actuar y decidir, los Enfermeros Especialistas del Trabajo.

Poco a poco, han ido llegando herramientas normativas que regulan estos aspectos tan necesarios tanto para la Enfermería del Trabajo como para la Salud de los Trabajadores. En consonancia a la Ley de Ordenación de las Profesiones Sanitarias, se desarrolla y publica el RD 450/2005 de Especialidades de Enfermería, en el que se recoge por primera vez la Especialidad con mayúsculas, tan demandada mucho tiempo. De esta 
manera la formación de los Enfermeros y Enfermeras Especialistas del Trabajo, se configura por primera vez para esta Especialidad, según el modelo del sistema EIR, autoaprendizaje tutorizado, sobradamente probado y positivamente valorado para otras especialidades de Ciencias de la Salud.

Como consecuencia de toda esta evolución, expuesta brevemente, por todo ello y sin perjuicio de los principios de interdisciplinaridad y multidisciplinaridad aplicables a los equipos profesionales que actúan en el ámbito de la salud laboral, los Enfermeros Especialistas del Trabajo ejercerán su profesión con plena autonomía técnica y científica por lo que deben adquirir y mantener las competencias necesarias para el adecuado ejercicio de sus funciones en los distintos ámbitos de actuación de la especialidad, como recoge textualmente la Orden SAS/1348/2009, de 6 de mayo, por la que se aprueba y publica el programa formativo de la especialidad de Enfermería del Trabajo.

Este programa formativo es el fruto dos años de estudio y reuniones de la Comisión Nacional de Enfermería del Trabajo, cuyo objetivo es recoger todos los aspectos del conocimiento que deberán alcanzar, al finalizar el periodo de formación, los futuros Especialistas con el objetivo que estos profesionales lleguen a realizar las actividades propias de su especialidad, dirigidas a prevenir, promover, proteger y restaurar la salud de la población trabajadora con un enfoque laboral y comunitario, integrado e integral, con una base científica y un conocimiento empírico.

A partir de ahora, un nuevo enfoque en la formación, abrirá también una forma avanzada de intervención especializada, con la inclusión de nuevas funciones correspondientes al área legal y pericial, así como al área de la Gestión, que confieren una nueva personalidad a la profesión.

Para ello es imprescindible que tanto las Comunidades Autónomas y las Unidades Docentes, arbitren los mecanismos necesarios para la dotación de plazas y se abra el camino a los residentes de la Especialidad de Enfermería del Trabajo.

Seguramente el día a día no va a observar grandes cambios, en principio. Se lleva haciendo "especialidad" desde 1959, desarrollando funciones con profesionalidad, seriedad y rigor, pero a partir de ahora, deberán hacerse con plena autonomía técnica y científica, y la Investigación en este campo podrá abrirse camino con mayor facilidad.

No podría finalizar, sin agradecer de forma muy especial a los conductores de esta realidad, MI MÁS PROFUNDA GRATITUD. Ha sido toda una singladura que han llevado a cabo con el altruismo de los generosos, de los que tienen intereses mucho más largos que los suyos propios, unos con su presencia y aportaciones personales y a todos los demás, por creer en esta necesidad.

FELICIDADES. 